\title{
FORMA, FUNCIÓN Y REALIDAD OBSERVACIONES SOBRE LA NOCIÓN PLATÓNICA Y ARISTOTÉLICA DE FORMA*
}

\author{
Marcelo D. Boeri \\ Universidad Alberto Hurtado
}

\begin{abstract}
Resumen: Este artículo se propone explicar qué son las "formas" platónicas y aristotélicas. Se argumenta que las formas describen tanto la función de algo como su "realidad". Por último, se analiza el impacto del formalismo antiguo en algunas manifestaciones del pensamiento contemporáneo como la interpretación neo-kantiana de la teoría de las formas de Platón, la lectura funcionalista contemporánea de la psicología de Aristóteles y la relevancia de la noción de paradigma en epistemología.
\end{abstract}

Palabras clave: forma, función, Platón, Aristóteles.

Marcelo D. Boeri. Doctor en Filosofía, Universidad del Salvador (Argentina), y Licenciado en Filosofía, Universidad de Buenos Aires (Argentina). Profesor del Departamento de Filosofía de la Universidad Alberto Hurtado (Chile). Es miembro de la International Plato Society y del Comité Editor de la International Plato Series. Cofundador y coeditor (1999-2008) de Méthexis (Revista Internacional de Filosofía Antigua) y Fellow de la John Simon Guggenheim Memorial Foundation. Dirección: mboeri@uahurtado.cl.

Deseo expresar mi gratitud a Ernesto Rodríguez Serra por invitarme a participar de este ciclo, y a Sylvia Eyzaguirre por facilitar la logística para mi presentación. También agradezco las preguntas y comentarios del auditorio.

* Este texto es una versión revisada de la conferencia presentada en el CEP en septiembre de 2011 en el marco del ciclo de conferencias "Formas de la realidad". Véase en esta misma edición la conferencia de Miguel Concha sobre el desarrollo de la forma en los seres vivos. Pronto se publicarán en Estudios Públicos las conferencias de Enrique Barros B. y Luis Izquierdo sobre la forma en el derecho y en la arquitectura, respectivamente. (N. del E.)

Estudios Públicos, 128 (primavera 2012). 


\title{
FORM, FUNCTION, AND REALITY: NOTES ON THE PLATONIC AND ARISTOTELIAN NOTION OF FORM
}

\begin{abstract}
This paper intends to account for what the Platonic and Aristotelian "forms" are. It is argued that forms describe both the function of something and its "reality". Finally, an analysis of the impact of the Ancient formalism on some manifestations of contemporary thought is provided (such as the neo-Kantian interpretation of Plato's theory of forms, the functionalist reading of Aristotle's psychology, and the relevance of the notion of paradigm in epistemology).
\end{abstract}

Keywords: form, function, Plato, Aristotle.

\section{Introducción}

$6 \sqrt{1-1}$ orma", "función" y "realidad" son nociones que aparecen estrechamente asociadas en el platonismo (que comienza con Platón y que, claramente, sigue con Aristóteles). Aunque en el vocabulario filosófico griego no hay una palabra específica para "realidad", es bastante obvio que lo que Platón y Aristóteles entendían por "forma" (idéa; ềdos) expresa "lo que real o absolutamente es" (para usar la venerable expresión platónica: tò óntos ón; tò pantelôs ón $)^{1}$, y que tal "realidad" con cierta frecuencia aparece asociada a la función de una cosa.

El propósito de este trabajo es muy simple: comenzaré por explicar qué es una "forma"; luego examinaré en qué sentido las formas son - tanto para Platón como para Aristóteles - una expresión de la función de algo y de su "realidad", y, finalmente, analizaré el impacto del formalismo platónico en algunas manifestaciones del pensamiento contemporáneo y sugeriré el significado que puede tener para nosotros todavía el dominio conceptual representado por la noción de forma. $\mathrm{Mi}$ exposición tendrá un carácter descriptivo, de modo de ser lo más claro

${ }^{1}$ República 477a3. Éstas son todas fórmulas que remiten a lo "verdadera o efectivamente existente", a "lo que es en sentido pleno o estricto", a "lo real" (en diálogos como Fedón, República o Timeo, por ejemplo, ese tipo de expresiones remite claramente a las formas o ideas, "lo máximamente real" en el sentido de lo que siempre es y nunca está sujeto al devenir y, por eso, "realmente es" (cf. Timeo 27d5-28a4 y 29c3). 
posible para un público no especializado, de manera que en mi presentación me abstendré de presentar una hipótesis que puede complicar el asunto más de lo necesario. Es cierto, no obstante, que cualquier explicación de un tema filosófico presupone siempre una tesis; para quien alguna vez haya paseado un rato por los textos de Platón o de Aristóteles seguramente serán claros mis presupuestos y mis hipótesis implícitas. Para quien nunca haya paseado por esos bosques (a veces oscuros e intimidantes) que constituyen los textos platónicos y aristotélicos, mis hipótesis implícitas son completamente irrelevantes, ya que mi único propósito es ofrecer una explicación simple de un tema complejo y cuyos alcances seguramente merecerían un tratamiento más pormenorizado y crítico. Sin embargo, creo que puede ser posible ofrecer una presentación de un tema difícil como éste sin traicionar el espíritu de los textos y proveer a la vez razones por las cuales el formalismo platónico $\mathrm{y}$ aristotélico puede ser aún hoy atendible para nosotros.

\section{Formas platónicas y aristotélicas: forma, función y "realidad"}

Es casi un lugar común en cualquier libro introductorio a Platón o a Aristóteles hablar de "formas" y sostener que tales entidades desempeñaron un papel decisivo en el modelo metafísico y epistemológico de dichos filósofos. Platón, por ejemplo, dice varias veces que el objeto propio del conocimiento son las formas o ideas ${ }^{2}$; dicho de otro modo, el sujeto $S$ conoce $X$ (siendo $X$ cualquier objeto del mundo), si y sólo si $S$ es capaz de captar (con su inteligencia, nos aclara Platón) la forma de $X$. También Aristóteles — que en éste, como en muchos otros puntos de detalle, sigue siendo, en mi opinión, un platónico convencido- con cierta frecuencia hace manifiesta su adhesión a ese enfoque platónico; revisemos los siguientes textos:

T1: Conocer (epístasthai) cada cosa consiste en conocer la esencia [de dicha cosa $]^{3}$. (Metafisica 1031b20-21).

${ }^{2}$ Cf. República 477a-b; 523b-524c; 602 e; Fedón 74b; 75b5-c1.

3 "Esencia" es una traducción aproximada de la intrigante expresión que usa Aristóteles en este pasaje (tò ti ên eînai): "lo que era ser" o "el qué era ser" para algo. Para una clara discusión y explicación de qué es ser una esencia aristotélica véase Gómez-Lobo (1998), pp. 55-58. A menos que indique lo contrario, las traducciones de los pasajes platónicos y aristotélicos citados textualmente me pertenecen. 
T2: El conocimiento (epistéme) consiste en conocer (gnorizein) el universal (kathólou). (Analíticos Posteriores 87b38-39).

T3: En efecto, afirmamos que sabemos (eidénai) cada cosa cuando creemos conocer (gnorízein) la causa primera. Pero las causas se dicen de cuatro modos y, en un primer sentido, decimos que es causa la esencia (ousía), es decir, el "qué era ser [algo]. (Metafisica 983a25-28).

Si uno examina estos tres pasajes en su contexto, resulta bastante claro que "universal", "esencia" y "qué era ser" no son algo muy diferente de una "forma" aristotélica. Es decir, conocer qué es algo y conocer la causa de si ese algo es lo que es, siendo esa causa su esencia o forma (i.e. la "causa formal") resultan ser lo mismo. Pero esto dicho así, y especialmente para alguien que no tiene un conocimiento experto en filosofía griega, casi seguramente resultaría incomprensible. Se trata, no obstante, de platonismo y aristotelismo básico. Una explicación general de qué significa "forma" en Platón y Aristóteles puede aclarar las dificultades que podrían estar generándose ya a esta altura. Aunque no pretendo entrar en todos los detalles y dificultades (que las hay en cantidades importantes), tal vez sea posible hacer una presentación sencilla del problema sin debilitar excesivamente el espíritu de la teoría.

"Forma" es la palabra con que habitualmente se traduce el término griego eîdos o su homólogo idéa; ambas palabras - ê̂dos e idéason sustantivos derivados de los verbos eído o joráo, que en griego significan "ver" en su sentido perceptivo, pero también "advertir" o "darse cuenta" en su sentido no perceptivo. Su raíz es id (presente en las palabras idéa y eîdos), e indica que tanto un ếdos como una idea es "lo que se ve", "el aspecto" de algo; nosotros podríamos decir, gracias a la potente (y al menos para mí a veces incómoda) presencia de anglicismos en nuestra lengua, "el look" de algo o alguien. Ése es el sentido con que se encuentra la palabra en Homero (uno de los registros escritos más antiguos que tenemos del griego antiguo), donde en un momento se dice que Alejandro es "deiforme" (theoeidés), es decir, "tiene la forma o aspecto de un $\operatorname{dios}^{4}$, o donde se habla de lo distinguido u óptimo que es "el aspecto (ềdos) del funesto Paris, loco por las mujeres"

\footnotetext{
${ }^{4}$ Homero, Ilíada, 3.27-30; 45.

${ }^{5}$ Ilíada 3.39.
} 
de otra manera, eîdos e idéa en su uso coloquial significa "aspecto" o, como también usa la palabra Platón, "aspecto corpóreo" o, más simplemente, "cuerpo" por oposición a "alma". Un testimonio elocuente de esto último es el siguiente pasaje:

T4: Sócrates, ¿qué te parece el jovencito? ¿No tiene un bello rostro?

-Bellísimo — respondí.

—Pero si éste estuviera dispuesto a desnudarse — dijo-, ya no te parecería de bello rostro: ¡tan completamente bella es su figura [i.e. su cuerpo $]^{6}$. (Cármides 154d).

Pero aunque Platón continúa usando las palabras que nosotros traducimos por "forma" o "idea" en su sentido coloquial para hacer referencia a aspectos sensibles (como un cuerpo o un rostro bello), también opera una profunda resignificación en dichos vocablos: en su uso técnico filosófico un eîdos o idéa ya no será más el aspecto externo de algo, sino, se podría decir, el "aspecto interno", es decir, la estructura conceptual de un cuerpo perceptible; según Platón, esas estructuras formales poseen una naturaleza diferente de la de lo corpóreo. Se trata entonces de la estructura conceptual que nos permite decir qué es $X$. Entendidos en este sentido, un ếdos o una idéa (Platón utiliza ambos vocablos como sinónimos) es lo que hace, en un sentido conceptual, que los múltiples $X S$ del mundo (las múltiples sillas y mesas, los perros, caballos y seres humanos) sean esas entidades o, mejor dicho, ese tipo o clase de entidad y ninguna otra más. Por eso Platón cree (y argumenta vigorosamente para tratar de probarlo) que no es lo mismo "la flor bella" que "lo bello" (o "lo bello mismo o bello en sí": autò tò kalòn), dos piedras iguales que "lo igual mismo o lo igual en sí"

Pero uno, sobre la base de un empirismo implícito que, por lo demás, puede ser muy razonable, podría preguntar: “¿cuál es la diferencia entre lo bello y la belleza de un rostro? ¿En qué difieren estas dos piedras iguales y lo igual?" 8 Y Platón responde: la diferencia crucial es

${ }^{6}$ La palabra aquí es ềdos, pero más adelante en el diálogo (157d) Platón usa idéa con el mismo significado de "aspecto".

${ }^{7}$ Cf. Platón, Fedón 74e-e; 78d; 100c.

8 Ésta es la distinción que, de acuerdo con Platón, "la mayoría" (o "la gente") no entiende o no admite: “-Así pues, habiendo entendido esto, recuerda aquello [otro]: ¿es posible que la mayoría (plêthos) tolere o crea que lo 
que un rostro bello en algún momento dejará de ser bello; lo bello, en cambio, siempre ha sido bello y siempre lo será, además de que lo bello siempre es lo mismo en todas las cosas que son bellas, i.e. en todas las cosas a las que uno puede atribuirles el predicado "bello/bella":

T5: Luego, ¿no será una forma eso que se piensa (nooúmenon) que es uno, y que es siempre lo mismo en todas las cosas? (aeì òn tò autò epì pâsin). (Platón, Parménides 132c6-7; trad. M. I. Santa Cruz, ligeramente modificada).

Un rostro, a pesar de los ingentes esfuerzos que uno haga por mantenerlo bello, en algún momento dejará de ser bello; y eso, cree Platón, significa que un rostro puede ser bello y feo, i.e. que admite predicados contrarios o, como suelen llamar los estudiosos a este hecho, las cosas perceptibles de nuestro mundo empírico a las que atribuimos el predicado "bello" admiten la "co-presencia de los opuestos". Y esto es así no sólo porque en algún momento esas cosas perceptibles dejarán de ser bellas, sino porque, al mismo tiempo en que puedo predicar con verdad que algo o alguien es bello, en un respecto diferente puede ser feo. Platón da el ejemplo de una muchacha bella que, no obstante, al mismo tiempo puede ser fea si se la compara con los dioses (Hipias Mayor 289a-c). Es decir, los particulares sensibles de nuestro mundo empírico (entre los cuales se incluye mi rostro) admiten la co-presencia de los opuestos; las formas o ideas, en cambio, no la admiten. Lo más que puedo predicar de ellas es lo que ellas mismas son: por ejemplo, lo bello es bello, lo igual es igual, lo justo es justo. Esto significa que las formas no puede tener propiedades contradictorias.

Pero ¿por qué Platón cree que su descubrimiento es relevante? Porque las formas o ideas, argumenta en el diálogo Fedón, en la República y en el Fedro (entre otros lugares), son el objeto propio del cono-

bello en sí (autò tò kalón), no las múltiples cosas bellas (tà pollà kalá), o que cada cosa en sí (autó tò hékaston), no cada una de las múltiples cosas (o "las múltiples cosas particulares"; tà poll’hékasta) exista? -No, en lo más mínimo, respondió. - Por consiguiente, repliqué, es imposible que la mayoría de la gente sea filósofo. - Es imposible"'(República, 493e2-494a5). Dicho de otro modo, Platón no tiene dudas de que la mayoría de la gente no está dispuesta a tolerar ni a aceptar que "lo bello mismo" (no las múltiples cosas bellas) o cada cosa en sí (no cada cosa múltiple) "exista", y mucho menos aún de que "exista" o "sea" en un sentido más "real" que cualquier objeto corpóreo. 
cimiento; es decir, conocer $X$ es saber qué es $X$, y para saber lo que es $X$ hay que ser capaz de captarlo con la inteligencia o pensamiento (con lo que Platón llama noûs; nóesis) ${ }^{9}$; dicho de otro modo, conocer $X$, es conocer su "qué", es decir, su estructura formal, su esencia, entidades a las cuales solamente tenemos acceso gracias a nuestra alma racional y a nuestras capacidades noéticas asociadas a ella. Esto conecta la llamada "teoría de las formas o ideas" de Platón con la teoría de la definición (otro genuino descubrimiento platónico), pues definir es proporcionar un enunciado que describa la esencia de una cosa, y dicha esencia es la forma o idea de la $\operatorname{cosa}^{10}$. En el pasaje platónico que cito a continuación es claro que saber o conocer algo es entenderlo, comprenderlo. Esto es patrimonio del "dialéctico", es decir, el filósofo de Platón, quien sabe o conoce en sentido estricto por cuanto es capaz de captar la esencia de cada cosa (i.e. su forma o idea):

T6: ¿Llamas 'dialéctico' al que capta la definición (lógos) de la esencia (ousía) de cada cosa? Quien no la capta, en la medida en que no es capaz de dar una definición de dicha cosa, ni para sí mismo ni para otro, no tiene comprensión (noûs) de esa cosa. (Platón, República 534b3-6.)

Una vez que uno ha llegado a este Olimpo metafísico, ya es completamente claro que cuando Platón dice "idea" no está pensado en el sentido psicológico que la palabra tiene en nuestra lengua y en otras lenguas modernas. Una idea o forma platónica no es un estado psicológico de un sujeto, sino un objeto metafísico transensorial que no se encuentra en el tiempo ni en el espacio, que no ha nacido en un punto del tiempo y que, por ende, tampoco morirá. Estos detalles constituyen el ABC del platonismo, y son la razón por la cual Platón sostiene que las cosas sensibles de nuestro mundo empírico, que se encuentran en perpetuo cambio, son parasitarias de las formas. Es por eso que muchas veces Platón argumenta que las formas son condición del conocimiento y su objeto propio, porque sólo puede haber conocimiento allí donde hay un cierto detenimiento o estabilidad, tanto del pensamiento como del objeto de conocimiento ${ }^{11}$. Hacia el final del Crátilo (440a6 ss.) el personaje

${ }^{9}$ Cf. Platón, Timeo 27d-28a.

${ }^{10}$ Véase arriba T1 y T2; cf. también enseguida T6.

11 La presencia de la "tesis del detenimiento" puede verse sugerida en Platón, Teeteto 189e3-190a6: cuando el alma piensa dialoga consigo misma, 
Sócrates afirma que ni siquiera es plausible decir que hay conocimiento si todas las cosas cambian y ninguna permanece. En efecto, si todo estuviera cambiando permanentemente (incluido el conocimiento mismo o la Forma de conocimiento) nadie podría conocer nada y nada podría ser conocimiento (440a9-b4).

Hay otro aspecto relevante conectado con lo anterior: una forma o idea platónica es un paradigma, modelo o patrón (parádeigma); así llama Platón a sus ideas o formas en varios y significativos pasajes. Se trata de una sugerencia que aparece por primera vez en un texto platónico tan temprano como el diálogo Eutifrón. Este texto es sorprendente porque, a pesar de pertenecer a ese conjunto de diálogos probablemente tempranos y, por tanto, "simples" de Platón, contiene ya los fundamentos de la teoría platónica de las formas ${ }^{12}$. La pregunta que da lugar a todo el proceso de investigación es “¿qué es la piedad?” Luego de los primeros exámenes que el personaje Sócrates lleva a cabo de las respuestas de Eutifrón a esta pregunta (y luego de mostrar las debilidades de dichas respuestas), se comienzan a delinear varios rasgos característicos de las formas:

(i) Tiene que haber una sola forma de piedad para todas las cosas piadosas (sea que se trate de acciones, de personas, etc.; 5d1-5).

(ii) La forma debe constituir un modelo, paradigma o patrón que podemos utilizar para decir si algo a lo que le atribuimos el predicado "piadoso-pío" lo es o no (6e3-6).

preguntándose y respondiéndose, tanto al afirmar como al negar. Pero cuando llega a definir o determinar algo, lo afirma y ya no vacila. Eso es lo que se establece como una "opinión" o "creencia" (dóxa) del alma. Opinar o sostener una creencia (doxázein) es hacer un discurso (légein), y la creencia (u opinión) es un discurso proferido y dirigido no a otra persona o en voz alta, sino en silencio a uno mismo (cf. también Platón, Sofista 263e). En Crátilo 437a, al examinar una probable etimología de la palabra epistéme, Platón indica que ella no sólo significa un cierto detenimiento o reposo del movimiento de nuestra alma en las cosas, sino también que todas las actividades intelectuales siempre presuponen un detenimiento (stásis) en el alma, no un movimiento.

12 Ciertamente, el Eutifrón no es el único diálogo temprano en el que se encuentran significativos adelantos de la "teoría de las formas" tal como la encontramos en los diálogos probablemente maduros (como Fedón, República, Crátilo o Fedro). También el Menón contiene varios pasajes importantes a este respecto; a modo de ejemplo, cf. 72c-d (la forma es aquello que es uno e idéntico en todas las ejemplificaciones de dicha forma); 74a (la forma es una unidad que se da a través de todas sus ejemplificaciones). 
(iii) La forma (eîdos) o idea (idéa) de piedad es "aquello por lo cual todas las cosas piadosas son piadosas" (6d9). Una descripción correcta de piedad debe exhibir el rasgo característico de las cosas piadosas que explica por qué lo son.

Estos tres rasgos característicos de toda forma platónica pueden reformularse de la siguiente manera:

(i) Una forma es una unidad: las ejemplificaciones de cada forma son múltiples (la forma de $x$, siendo $x$ lo piadoso, lo justo, etc., es única).

(ii) La forma es un modelo o paradigma (República 472c-d, 484c, 500e, 529d; un "arquetipo", como dirá mucho más tarde Filón de Alejandría) ${ }^{13}$, del cual el particular sensible es su imitación o copia, una apariencia de la realidad que es la forma o idea (mímesis; mímema. República 595c-598a ${ }^{14}$. Si la forma es un modelo o patrón, los particulares sensibles "tienden" o "aspiran" a ella (Fedón 74e).

(iii) La forma es un "por lo cual", es decir es la esencia que reúne la multiplicidad de particulares.

La historia es mucho más compleja y tiene muchas aristas que no puedo sino omitir para pasar a Aristóteles en la siguiente sección, dar algunas precisiones adicionales y terminar con una conclusión y alguna sugerencia sobre la presencia del formalismo antiguo en la filosofía posterior. Antes de pasar a Aristóteles querría, sin embargo, mencionar brevemente una de las complicaciones de la teoría, sin duda advertida por Platón en sus propios diálogos: si efectivamente hay un dominio senso-perceptible, al que pertenecen los objetos de nuestra experiencia perceptiva, y un dominio eidético que es diferente y, por ende, que se encuentra al margen del dominio sensible, ¿cómo se conecta un dominio con el otro? ${ }^{15}$ Platón imagina al menos tres modos de conexión entre un ámbito y otro: (i) participación (las cosas sensibles participan de los

${ }^{13}$ Cf. Filón de Alejandría, Sobre la Creación del Mundo 16; Alegoría de las Leyes 1.22.

${ }^{14}$ En Timeo 48e-49a el mundo visible es caracterizado como una "imitación de un modelo" (mímema paradeígmatos).

15 En Fedón 74a9-12 Platón establece claramente que una cosa es lo igual (la forma o idea de "igual") y otra cosa son dos leños o piedras a las que se atribuye el predicado "igual"; también aclara que "lo igual mismo" está al margen o más allá (parà taûta) de las piedras o leños iguales. Es sin duda este tipo de pasaje platónico el que da pie a Aristóteles para postular el problema de la "separación" (jorismós) entre ambos dominios. 
ítems inteligibles-pensables, las formas o ideas, de las cuales reciben el nombre que poseen), (ii) comunidad (hay una comunidad o asociación entre ambos dominios, ya que es gracias a la forma que puedo decir y denominar a un objeto sensible, e identifico cada particular sensible por la comunidad o asociación que dicho particular tiene con la forma), y (iii) hay una "presencia" de la forma o idea en la cosa sensible. ${ }^{16}$

Ya he dicho que Aristóteles cree, igual que Platón, que conocer es captar intelectualmente la forma o estructura conceptual de una cosa. Y esto es así, en su opinión, porque, como también pensaba Platón, ser algo en su sentido prioritario es ser una forma o una estructura formalconceptual, i.e. es ser algo que es en sentido prioritario. Pero dado que Aristóteles cree que las formas se dan o existen en el particular sensible, en varias ocasiones argumenta que ser un "esto determinado" y la esencia formal de dicho ente determinado son lo mismo ${ }^{17}$. Si el "esto determinado" es mi amigo Juan (que es un particular concreto de la forma "hombre"), Juan es prioritario respecto de su peso, porque el peso se dice o predica de Juan pero no Juan de su peso. Juan puede bajar o subir de peso, pero seguirá siendo Juan. En parte tratar de probar esta tesis es tarea de uno de los libros centrales (y más difíciles) de la Metafísica aristotélica, el libro VII.

Ahora bien, para abordar el tema de la forma en Aristóteles conviene centrarse en la batalla que éste libra contra Platón. Se trata de una historia difícil en sus detalles que, sin embargo, procuraré resumir en pocas líneas y en dos momentos (1) y (2).

(1) Platón tiene razón cuando argumenta que conocer $X$ es captar la forma de $X$; se equivoca, sin embargo, al creer que es necesario separar el dominio de nuestra experiencia senso-perceptible del dominio eidético ${ }^{18}$. Dicho de otra manera, a Aristóteles le incomoda la "separación" que Platón opera entre el "mundo" sensible y el inteligible o formal $^{19}$. En el mismo contexto de esta objeción Aristóteles elabora una

${ }^{16}$ Véase Platón, Fedón 100d; 101c. Es el propio Platón quien se ocupa de desplegar la primera crítica sistemática a estos modos de conexión entre los dos dominios (sobre todo a la noción de "participación"; cf. Parménides 131a-b).

${ }^{17}$ Metafísica 1030a18-19; 1031a15-18 y T7 infra.

18 Véase Metafísica 987 b12-18; 1078 b30 ss.

${ }^{19}$ La expresión "mundo de las ideas" (habitual para referirse al idealismo platónico) debe ponerse entre comillas, pues Platón nunca la utiliza. Sí menciona, sin embargo, un "lugar supra-celeste" (hyperouránios tópos) en el 
teoría que tiene un alcance extraordinario en su propio proyecto filosófico: el llamado "hilemorfismo", esto es, la teoría metafísica según la cual cualquier entidad perceptible es un compuesto de dos ítems: materia (hýle) y forma (morfé, otra palabra empleada por Aristóteles para referirse a sus formas), compuesto en el cual tanto la materia como la forma funcionan como principios explicativos y no como "cosas" del mundo. Pero para que eso sea posible, argumenta Aristóteles, la forma debe estar en el compuesto, es decir, la forma es inmanente al compuesto. Un pasaje clave para advertir la relevancia del inmanentismo aristotélico es el siguiente:

T7: La sustancia (ousía), en efecto, es la forma inmanente (tò ếdos tò enón); a partir de ella y de la materia se llama 'sustancia' a la [sustancia] compuesta; por ejemplo, la concavidad (pues a partir de ésta y de la nariz se da la nariz chata y la chatedad), pero en la sustancia compuesta - por ejemplo, en una nariz chata o en Calias - también estará presente la materia; y la esencia y la cosa particular en algunos casos son lo mismo. (Metafísica 1037a29-b1).

Este pasaje es sin duda complicado, aunque su contenido básico en vista de ejemplificar el inmanentismo aristotélico puede explicarse de la siguiente manera: (a) la "sustancia" (i.e. algo que es o existe en un sentido prioritario) es la "forma inmanente", es decir, es una forma que se da o está en algo que existe como algo determinado (esta mesa, esta nariz). (b) A partir de la forma y de la materia se denomina "sustancia" a la que se compone de materia y forma (i.e. a los particulares perceptibles). Aristóteles pone como ejemplo de forma "la concavidad" (es decir, "ser cóncavo"), y argumenta que a partir de ella y de nariz se da o existe la "nariz chata" y "la chatedad", y que en una nariz chata, digamos la de mi vecino Calias, también estará presente la materia. Es una manera un poco enrevesada de decir que tanto "nariz chata" como "cha-

que se encontrarían las formas (cf. Fedro 247c). Ese giro sin duda introduce dificultades, toda vez que conferir categorías locativas ("lugar") a algo que no se encuentra en un lugar siempre conlleva complicaciones. Claro que Platón siempre podría replicar que lo de "lugar" no debe tomarse al pie de la letra y que, al tratarse de un sitio "supra-celeste", debe ser un cierto dominio que incluso se encuentra por encima del cielo — que es corpóreo-, una "dimensión" que se encontraría incluso más allá del cielo. 
tedad" dependen la una de la otra para existir. No hay nariz chata sin la presencia de la chatedad en ella, ni chatedad sin una nariz concreta en la cual pueda darse la chatedad (que es una forma) ${ }^{20}$. Por eso en un tercer momento (c) Aristóteles agrega que la esencia (la forma "chatedad") y la cosa particular (la nariz de mi vecino Calias) en algunos casos son lo mismo. Si eso es así, no hay, por tanto, necesidad de duplicar el mundo, como, según Aristóteles, hace Platón. Sin duda hay formas, pero en los compuestos, esto es, en los particulares sensibles.

Como sabemos, de este tipo de objeción deriva la llamada "navaja de Ockam" "21: entia non sunt multiplicanda sine necessitate: "los entes no deben ser multiplicados sin necesidad”. Pero ¿por qué conviene suponer que las formas deben darse en el compuesto? En primer lugar, uno podría presumir, por una economía explicativa: si la forma está en el particular perceptible, lo que debo hacer es explicar un solo dominio, no dos. En segundo lugar — éste es el argumento más potente de Aristóteles-, no es simple dar cuenta de la existencia de una forma independientemente del objeto en el que se da e, inversamente, un objeto determinado no es el objeto que es sin la presencia de su correspondiente forma. Vamos a ver con más claridad esto enseguida, cuando conectemos la noción aristotélica de forma con la de función. Pasemos ahora a la segunda objeción aristotélica contra Platón, que constituye un desarrollo de la primera.

${ }^{20}$ La explicación se entiende mejor si se recuerda que para Aristóteles "chato" es un predicado propio de una nariz (ya que "chatedad" es el resultado de la adición de concavidad y nariz; Metafísica 1030b16-18). Éste es un caso de "accidente esencial", i.e. un atributo o propiedad "que pertenece a cada cosa por sí sin estar en su sustancia" (Metafísica 1025a31-32); el ejemplo aquí es que un triángulo tenga sus ángulos interiores igual a dos rectos. Es decir, tener los ángulos interiores igual a $180^{\circ}$ es un accidente del triángulo porque tal característica no entra en la definición de triángulo (eso significa que es algo que pertenece por sí a la cosa pero no está en su sustancia); pero ese accidente es esencial porque no hay triángulos que puedan no tener sus ángulos iguales a dos rectos (véase también Metafísica 1037a29-33 y Analíticos Posteriores 73a34-b1). Para una discusión detallada del ejemplo de la nariz chata, véase Irwin 1988: 238-240; Charlton 1995: 246.

${ }^{21}$ La expresión recuerda al filósofo escolástico Guillermo de Ockam (s. XIII-XIV), a quien se asocia a un enfoque nominalista vigoroso, una de cuyas tesis básicas es que solamente existen los individuos y que los universales sólo son abstracciones de los particulares y se reducen a ser meros nombres. 
(2) Para advertir solamente un detalle del alcance del hilemorfismo de Aristóteles quiero referirme a un aspecto, decisivo en mi opinión, de su psicología (esto es, su teoría del alma), a saber, el alma es la "forma" del compuesto que es el ser vivo. Esto nos permitirá advertir también la conexión que hay entre el hilemorfismo y el funcionalismo aristotélico. Nosotros sabemos que, de acuerdo con los supuestos básicos de la ontología aristotélica, una forma es aquello que le permite al objeto del que es forma ser ese objeto. Para tomar algunos ejemplos que da Aristóteles en su De Anima ${ }^{22}$, la forma de un hacha es lo que le permite al hacha ser hacha (i.e. funcionar como hacha), la del ojo la que lo habilita a ser ojo (i.e. ver). De la misma manera, el alma como forma es lo que le permite al ser vivo ser un ser vivo (i.e. vivir), lo que hace que un cuerpo natural y un ser vivo como el ser humano sea capaz de cumplir con sus funciones propias: (1) crecer, desarrollarse, nutrirse; (2) sentir y/o percibir, y (3) pensar, comprender, planear ${ }^{23}$.

La conexión que establece Aristóteles entre la forma de algo y su función está claramente adelantada por Platón. En un notable pasaje de la República (352e-353e) el personaje Sócrates argumenta a favor de la tesis de que la justicia es más ventajosa y mejor, y que, por tanto, el justo vivirá mejor. Para probar esta hipótesis presenta un argumento que llamaré "argumento de la función y perfección propia de cada cosa", que puede ordenarse en los siguientes pasos: (i) cada cosa tiene una función propia (érgon). (ii) Dicha función corresponde a lo que puede hacerse de la mejor manera (árista; kállista); por ejemplo, aunque los sarmientos de la vid pueden cortarse con un cuchillo o con una espada, es mejor hacerlo con la hoz o la podadora, que son instrumentos especialmente diseñados para desempeñar esa función (352e-353b). (iii) Si esto es así, también puede decirse que hay una excelencia o perfección (areté) propia de cada cosa a la que se le asigna una función. Cada cosa, entonces, desempeña bien la función que le corresponde gracias a la excelencia o perfección que le es propia (353c). (iv) Pero si las demás cosas tienen una función que les es propia, también el alma debe tenerla (como cuidar, mandar, deliberar y, fundamentalmente, vivir). (v) El alma, sin embargo, no puede cumplir bien sus funciones propias si

${ }^{22}$ El título en latín con el que se conoce su tratado Acerca del Alma (en griego Peri psyjês).

${ }^{23}$ Estos tres "niveles de vida" son tratados en detalle por Aristóteles en el libro II de su De Anima. 
está privada de su excelencia o perfección (353e). Por lo tanto, (vi) un alma mala deberá gobernar y cuidar mal de las cosas; un alma buena, en cambio, lo hará bien. Finalmente (vii), si se había convenido en que la justicia es una perfección o excelencia (areté) del alma y la injusticia una imperfección o deformidad (kakía), entonces, el alma justa y la persona justa vivirán bien, en tanto que la persona injusta vivirá mal. Como se ve, Platón no dice expresamente que la función de una cosa es sin más su forma, pero ese enfoque está claramente sugerido, ya que el individuo que ejerce bien la función que le es propia es una correcta ejemplificación de la forma, en virtud de la cual es el individuo que efectivamente es $^{24}$.

Regresemos a Aristóteles: si el alma es lo que le permite a un ser vivo cumplir con sus funciones propias, eso significa que la forma es inseparable del cuerpo porque, aunque el alma no es cuerpo, no se da si no es a través del cuerpo ${ }^{25}$. El énfasis es importante para advertir en qué difiere la posición psicológica de Aristóteles respecto de la de Platón; en efecto, dicho énfasis elimina la posibilidad de pensar en términos de lo que los filósofos de la mente contemporánea llaman "dualismo sustancialista", tal como dicho dualismo puede advertirse en un diálogo como el Fedón, por ejemplo: hay dos sustancias (dos "cosas" diferentes), alma y cuerpo, que pueden existir de un modo independiente. Aristóteles, como Platón, también cree que el alma y el cuerpo son dos ítems diferentes; pero además piensa que el uno no se da sin el otro: el cuerpo sin su forma (el alma) no es cuerpo más que en un sentido homónimo o equívoco, porque no funciona como un cuerpo. Pero, a su vez, sin un cuerpo el alma no posee el soporte material a través del cual puede desplegar sus poderes, esto es, las funciones anímicas necesitan un cuerpo como condición necesaria (el ejemplo favorito de Aristóteles son los estados afectivos, emociones, pasiones — páthe_-, que son estructuras formales "enmateriadas", i.e. formas que se dan o existen en la materia: lógoi ényloi, De Anima 403a25). En su interpretación de la forma y en su distanciamiento del platonismo, Aristóteles dirá ahora que el alma,

${ }^{24}$ Hay un enfoque similar en el llamado "argumento de la función" en Aristóteles (Ética Nicomaquea 1097b24-1098a18; 1106a15-24. Véase también Física 246a13-189).

${ }^{25}$ Cf. De Anima 403a16-19; 414a19-20. Para una discusión pormenorizada de este importante dictum de la psicología aristotélica me permito enviar a Boeri (2009). 
como cualquier otra forma en su esquema ontológico, debe darse en el particular, i.e. esta alma en esta persona, esta alma en este animal, esta otra alma en esta planta. A diferencia de Platón que sin duda sostiene que el alma puede existir aparte del cuerpo y que además produjo un conjunto de argumentos bastante detallados para probar la inmortalidad del alma, Aristóteles tiene al menos algunas dudas a ese respecto ${ }^{26}$. A pesar de sus dudas iniciales, teniendo a la vista su hilemorfismo, Aristóteles termina por rechazar la posibilidad de que el alma siga existiendo como un individuo numérico (i.e ésta o aquella alma particular) una vez separada del compuesto que es cada ser vivo particular. La objeción aristotélica de fondo va por el lado de su defensa de un inmanentismo vigoroso: las formas $-\mathrm{y}$ en no menor medida la forma que es el almase da (o existen) en el compuesto ${ }^{27}$.

La relevancia que este enfoque tiene también en la teoría psicológica aristotélica difícilmente puede ser exagerada; veamos el argumento en contra de la inmortalidad del alma: (a) lo único y lo mejor que puede hacer un ser viviente que sea completo y no se encuentre mutilado ni sea el resultado de la generación espontánea es replicar su propia forma (i.e. su alma) en otro miembro de la misma especie mediante la producción de otro ejemplar como él mismo (De Anima 415a28). (b) Éste es el modo en el que un individuo de la especie puede, en la medida de lo posible, "participar de lo eterno y lo divino". (c) Pero su forma no tiene existencia separada de su cuerpo, porque es imposible participar de lo eterno y de lo divino de manera continua (ya que nada destructible puede persistir siendo lo mismo y uno en número). (d) El único modo en el que uno puede "persistir" es siendo no el mismo individuo, sino "permaneciendo" en otra cosa que sea como él mismo. (e) Ahora bien, es

${ }^{26}$ Para los argumentos platónicos a favor de la inmortalidad del alma cf. Fedón 69e5-107b10; República 608d-611a; Fedro 245c5-246a2; Leyes 894a898c. Sin embargo, es el mismo Platón (Fedón 77c1-5) quien advierte sus dudas respecto del modo en el que el alma eventualmente continuaría existiendo: aun aceptando que el alma existía antes de que uno naciera, Cebes hace la razonable observación de que se requiere una prueba adicional para mostrar que después de la muerte el alma sigue existiendo "en no menor grado" (77c4) después que uno ha muerto. Dicho de otro modo, después de admitir que el alma continúa existiendo tras la muerte, la cuestión relevante es si ella conserva o no sus poderes anímicos. Para un desarrollo de éste y otros aspectos relacionados con las críticas aristotélicas a la psicología platónica y los desarrollos estoicos (probablemente montados en las objeciones de Aristóteles) véase Boeri (2010).

${ }^{27}$ Cf. supra nuestro T7 y Metafísica 1078b30-32; 1079b15-19. 
imposible que lo sea "numéricamente" (es decir, "como un individuo", pues la sustancia de lo que es se da en el particular), y $(f)$ es imposible que se mantenga la eternidad de la especie en el mismo individuo, aunque es posible que se conserve en la especie o, más precisamente, en otro individuo de la misma especie. ( $g$ ) Pero como los individuos no son eternos, siempre hay un género de seres humanos, de animales y de plantas, y es para conservar la existencia de tales géneros que se produce (de modo permanente) la reproducción ${ }^{28}$.

En realidad, la sospecha de que el alma individual no puede seguir existiendo tras la muerte aparece bastante temprano dentro del De Anima; en el pasaje 403a5-10 Aristóteles argumenta que el alma no puede experimentar una afección o ejercerla sin el cuerpo, aunque hay una facultad que por excelencia parece propia del alma (racional): pensar o inteligir (noeîn; 403a8). Creo que este texto es importante, pues Aristóteles sugiere que si el pensar es una forma de "imaginación" (fantasía) o que resulta imposible sin ella (como finalmente lo establece), el pensar requiere de un cuerpo. En efecto, si la imaginación presupone la sensación y la sensación un cuerpo, se sigue que el pensar no se da sin un cuerpo. La conclusión del argumento parece ser que el alma (psyché) no existe separadamente, salvo que haya funciones o afecciones propias de ella. Pero como las afecciones del alma suponen un cuerpo, el alma no puede existir separadamente de él. Uno puede concluir que en su distanciamiento de Platón Aristóteles no sólo relativiza la posibilidad de que alma y cuerpo puedan darse separados, sino que además funda un nuevo sustancialismo metafísico que reconoce el alma y el cuerpo como dos ítems esencialmente diferentes, pero también como co-dependientes.

Por último, no deja de ser interesante señalar que algunos principios del funcionalismo contemporáneo (Hilary Putnam) parecen coincidir con la tesis de Aristóteles, según la cual todo se define por su función (érgon) y cada cosa es lo que verdaderamente es cuando es capaz de llevar a cabo su función propia:

${ }^{28} \mathrm{He}$ reconstruido el argumento a partir de De Anima 415a25-b7 y del tratado aristotélico Acerca de la Generación de los Animales 731b31-732a3; una discusión detallada del problema se encuentra en Botter 2009: 85-91. Es clara (y bien conocida) la filiación platónica del trasfondo de este argumento aristotélico (cf. Platón, Simposio 208a-b). Siguiendo en parte a Platón, Aristóteles suscribe la tesis de que la inmortalidad se da en la repetición de la forma en un individuo nuevo; aunque en el texto platónico no hay distinción entre existencia numérica y específica, la idea es la misma. 
T8: Todas las cosas se definen por su función (érgon), pues cada cosa existe verdaderamente cuando es capaz de realizar su propia función; por ejemplo, un ojo si ve. Lo que no puede [realizarla], en cambio, [solamente existe] en un sentido homónimo, como [el ojo] muerto o el de piedra. Desde luego que tampoco es sierra la de madera, a no ser que se trate de una imagen. Así también sucede con la carne, aunque su función es menos evidente que la de la lengua. (Aristóteles, Meteorologica 390a10-142).

Un aspecto importante del funcionalismo contemporáneo es la llamada "múltiple realizabilidad de lo mental", i.e. los estados mentales (Aristóteles tal vez diría "estados anímicos", pero para el caso es lo mismo) pueden realizarse en sistemas diferentes pues lo decisivo no es el material del sistema, sino que éste sea capaz de llevar a cabo la función. En este sentido es irrelevante si un reloj es de madera o de acero; lo relevante es que sea capaz de dar la hora correctamente, que es su función:

T9: Dos sistemas son funcionalmente isomórficos si hay una correspondencia entre los estados de uno y los estados del otro que conserve las relaciones funcionales. (Putnam 1995: 291; cf. también 292-293).

Algunos estudiosos de Aristóteles (M. Cohen 1992 y M. C. Nussbaum y H. Putman 1992) que simpatizan con el funcionalismo contemporáneo creen que puede leerse Aristóteles a la luz de la múltiple realizabilidad de lo mental. Se trata de un problema que tiene aristas complicadas, aunque creo que hay razones textuales y conceptuales que muestran que Aristóteles no habría adherido a este tipo de funcionalismo y mucho menos a la tesis de la múltiple realizabilidad de lo mental. Se trata de un tema complejo, cuyo desarrollo requeriría un considerable espacio ${ }^{30}$, aunque puede plantearse la siguiente objeción a la interpretación funcionalista de la psicología aristotélica: en primer lugar, hay que reparar en el hecho de que para Aristóteles "alma" no es lo mismo que "mente" (la psyché puede ser vegetativa — con sus procesos de nutrición, crecimiento, decrecimiento, etc.—, sensitiva — con sus procesos

29 Véase también Acerca del Movimiento de los Animales 703a34-b2; Acerca de las Partes de los Animales 641a2-3; 654b4, 657a6 et passim.

${ }^{30} \mathrm{He}$ discutido en detalle el tema en Boeri (2009). 
característicos de sensaciones de dolor o placer, de tacto en sus variadas formas, etc. - o racional — con la actividad característica de pensar, ya sea en sentido teórico o práctico, i.e. el pensamiento que se hace en vista de algo-) y que, por lo tanto, el alma solamente puede darse en un ser orgánico natural con funciones orgánicas bien definidas. Si desde la perspectiva aristotélica fuera cierto que no importa el tipo de sistema material de que se trata, sino simplemente que dicho sistema sea capaz de cumplir apropiadamente la función del caso, habría que encontrar referencias textuales y discusiones teóricas relevantes en los textos que permitan decir que Aristóteles admitía que ciertos artefactos son capaces de desplegar funciones anímicas vegetativas, senso-perceptivas o intelectuales. Los filósofos de la mente contemporáneos no tienen demasiado problema en atribuir cierto tipo de función intelectual a los artefactos, pero Aristóteles sin duda lo tiene, pues para él el pensamiento es prácticamente una función biológica de ciertos seres vivos que, como condición previa, deben ser capaces de desplegar funciones anímicas vegetativas y senso-perceptivas.

Algunos defensores de la lectura funcionalista de la psicología aristotélica citan con entusiasmo un pasaje de Metafísica VII 11 (1036a33), donde Aristóteles sostiene que "ni el bronce ni la piedra pertenecen a la sustancia ${ }^{31}$ del círculo", y de esta línea infieren que lo que quiere decir es que la forma "círculo" sobreviene a diferentes tipos de materia, de lo cual, a su vez, se seguiría que, aunque Aristóteles afirma que la forma de hombre (i.e. "ser hombre", "humanidad") aparece siempre en carne, huesos y otras partes semejantes (1036b3-4), "en cierto nivel abstracto" fue al menos concebible para él la posibilidad de la múltiple realizabilidad de lo mental ${ }^{32}$. Sin embargo, esta optimista expectativa de que a partir de este pasaje uno pudiera albergar la esperanza de que Aristóteles hubiera adherido de algún modo a la tesis de la "múltiple realizabilidad de lo mental" debe ser descartada, pues, como lo indican las definiciones aristotélicas de alma, no puede decirse que cualquier tipo de sistema físico tiene psyché, pues ésta siempre se da asociada a un cuerpo físico, pero no a cualquier tipo de cuerpo físico, sino solamente a aquel que sea capaz de admitir funciones fisiológicas. Es cierto, como señala Cohen, que Aristóteles está interesado en argu-

${ }^{31}$ Aquí "sustancia" (ousía) debe significar "forma".

${ }^{32}$ Cf. Cohen, 1992: 59-60. 
mentar que las definiciones deben ser siempre en términos de función, no de materia, pero no es menos cierto que también está interesado en enfatizar que cierto tipo de funciones (como las anímicas) solamente se dan en cierto tipo de sistemas materiales, i.e. sistemas orgánicos ani$\operatorname{mados}^{33}$. Aristóteles no puede ser más claro al respecto: el alma es una "actualidad" (i.e. una "realidad") primera de un cuerpo natural (sôma fisikón) que en potencia tiene vida y es de tal índole lo que es orgánico, i.e. un cuerpo natural orgánico (organikón; DA 412a27-b6) ${ }^{34}$. En Metafísica 1040b6-8 Aristóteles parece sugerir que cuando las partes de un cuerpo ejercen su función dentro del cuerpo, es adecuado decir que, realmente, están en posesión de su función y que, por ende, son un cierto tipo de parte que coincide con cierto tipo de órgano. Pero solamente lo son como partes materiales de un organismo, independientemente del cual ya no son lo que podrían ser. En efecto, separadas del cuerpo en el cual son capaces de llevar a cabo sus funciones, se convierten en mera materia ${ }^{35}$. Es cierto, entonces, que Aristóteles describe algunos

${ }^{33}$ Cf. Metafísica 1035b14-18, donde Aristóteles argumenta que cada parte, si se define correctamente, no se definirá sin su función (lo cual da en parte la razón a Cohen), pero también sostiene que dicha función no existirá sin sensación, la cual es propia de cierto tipo de sistema material, a saber, un cierto tipo de sistema orgánico (para Aristóteles las plantas también son sistemas orgánicos, pero carecen de sensación que es la marca distintiva del animal; cf. De Anima 410b25; 413b2). Además, Aristóteles también está interesado en recordar que "cualquier alma al azar no puede entrar en cualquier cuerpo al azar" (De Anima 407b22-23). La afirmación se hace en el contexto de la refutación de la tesis pitagórica de la reencarnación (Aristóteles parece pensar que, según los pitagóricos, el alma podría reencarnar en cualquier tipo de cuerpo), pero es de todas maneras válida para la teoría general del alma que Aristóteles defiende: solamente puede entenderse una forma como "alma" si el compuesto del que es forma es un compuesto natural animado orgánico.

34 Como correctamente señala Charlton, las "expresiones anímicas" se dan en respuesta a la pregunta “¿cuál es su forma?” cuando dicha pregunta surge respecto de objetos materiales (i.e. cuerpos) que son naturales, i.e. no artefactos o seres inanimados (1995: 246).

35 Como no podía ser de otra manera, el texto es mucho más lacónico; simplemente dice "Es manifiesto que en su mayoría las que parecen ser sustancias también son potencias (o facultades; dynámeis): las partes de los animales, pues ninguna de ellas existe separadamente; pero cuando se separan, en ese momento todas ellas existen como materia" (Metafísica 1040b5-8; en la comprensión de estas líneas sigo la interpretación de Patzig-Frede 1988: II 298). Un problema no menor es que Aristóteles parece tratar todas las partes del animal -incluidas las partes homeómeras, como "carne" o "hueso"- como si estuvieran definidas por sus funciones y, de este modo, como si se tratara de ítems animados (i.e. dotados de alma; en este punto sigo a Whiting, 1992: 77-78). 
casos difíciles, en los que las partes son eventualmente capaces de tener una existencia independiente, de manera que son unidades por naturaleza pero no son necesariamente unidades orgánicas (Metafísica 1040b10-15); no obstante, las partes del ser vivo tienen unidad solamente en cuanto partes del todo (i.e. el cuerpo). Para poner el ejemplo de Aristóteles, una mano es mano en sentido estricto únicamente en la medida en que funciona como tal como parte de la unidad orgánica; separada del todo, se descompone en sus elementos materiales los que solamente gracias a la forma del todo orgánico son capaces de "ser mano", i.e. de ser una parte orgánica de un todo orgánico. La unidad natural, por consiguiente, es la unidad de una sustancia (ousía), sustancia cuya forma es el alma.

\section{Epílogo: ¿cuán "real" es para nosotros el formalismo platónico-aristotélico?}

Uno debería preguntarse ahora qué relevancia tiene la teoría platónico-aristotélica de las formas en nuestro modo de ver el mundo. El impacto más directo del formalismo platónico-aristotélico se dio, obviamente, en la historia de la filosofía posterior y en parte también en la historia de la ciencia (aunque esta distinción nunca es clara en los antiguos, pues filosofía y ciencia no eran todavía por aquel entonces dominios diferentes). Uno de los problemas fundamentales que inaugura el formalismo antiguo es el de los universales, esas entidades abstractas supuestamente existentes, pero cuyo modo de existencia no es nunca completamente claro, no obstante lo cual usamos permanentemente dichos "universales" para conceptualizar el mundo. Ésta es una primera contribución de Platón y Aristóteles a nuestro modo de comprender el mundo: pensamos en términos de estructuras. Advertir que no es lo mismo esta cosa particular del mundo, i.e. esta mesa sobre la que apoyo mis papeles, de un particular entendido en términos de clase o tipo ("mesidad", "ser mesa") no es trivial, pues me permite categorizar tipos de cosas y distinguir un objeto de otro.

Aunque hacia el final de la sección anterior ya he adelantado la relevancia de la presencia de la teoría aristotélica del alma (o mente) como forma en algunas discusiones contemporáneas de filosofía de la mente, querría concluir señalando otros dos impactos relevantes del formalismo antiguo en la filosofía contemporánea. 
1. El filósofo neo-kantiano Paul Natorp publicó un libro notable a comienzos del siglo XX llamado La teoría de las ideas de Platón: Una introducción al idealismo ${ }^{36}$. Son muchas la tesis que discute Natorp en su libro y, entre otras cosas, intenta mostrar que hay razones para entender las formas platónicas en términos del a priori kantiano, i.e. una idéa es un ítem paradigmático de algo que es absolutamente independiente de la experiencia. Aunque en la obra no hay una discusión puntual de la noción de a priori, es relativamente claro que es eso en lo que piensa su autor toda vez que homologa la idea platónica a la ley (Gesetz) o a la "forma de la legalidad en general" 37 . Como es obvio en el contexto, Natorp no está restringiendo el término "ley" a estatutos legales o a las leyes de la naturaleza; lo que quiere decir con "ley" es cualquier cosa que se "pone" o "establece" 38 de modo racional, incluyendo los axiomas matemáticos. En el enfoque kantiano de Natorp ese "poner racional" debe constituir la experiencia (Erfahrung), lo cual ocurre cuando los conceptos (puros del entendimiento) se establecen y relacionan con los datos sensibles ${ }^{39}$. Dado que estas "leyes" (i.e. las ideas platónicas) son condiciones de posibilidad de cualquier objeto empírico (esto es, sin ideas o leyes no puede constituirse un objeto de experiencia), deben ser a priori. El esquema explicativo es kantiano, pero el paralelo con Platón es importante: los particulares sensibles platónicos dependen de las formas o ideas platónicas para ser lo que son, y éstas no son objetos de experiencia, sino más bien lo que posibilita tales objetos de experiencia.

Seguramente, a Platón nunca se le ocurrió formular el tema en esos términos, pero sin duda hay un núcleo de verdad en el enfoque de Natorp: para que haya mundo ("empírico, se entiende) nuestra mente parece precisar de estructuras que, al menos en principio, entendemos como independientes de los objetos empíricos, estructuras que en un enfoque idealista como el de Natorp o incluso como el de Platón, son

${ }^{36}$ Natorp (1903).

${ }^{37}$ Natorp (1903): 27-28.

38 Seguramente, Natorp tiene presente la conexión existente en alemán entre Gesetz ("ley") y setzen ("poner", "establecer").

${ }^{39}$ Natorp ya detecta la oposición o contraste (Gegensatz) entre la idea y la experiencia en un diálogo platónico probablemente temprano como el Protágoras (cf. 1903: 18). 
siempre anteriores a los objetos empíricos ${ }^{40}$. La idea, entonces, como forma de la legalidad en general es lo que permite categorizar el mundo en tipos o clases de objetos.

2. Para concluir, comentaré brevemente otra contribución relevante del formalismo platónico. Al concluir mi tratamiento de Platón, mencioné que las formas platónicas son paradeígmata, "paradigmas", "modelos". En un notable pasaje de la República (472c-d) Platón dice lo siguiente:

T10: Por consiguiente, concluí yo, fue en vista de un modelo que estábamos buscando [eso] mismo, i.e. qué es la justicia y la persona completamente justa, en caso de que existiera, y cómo sería si existiera; y a su vez [de manera similar] con la injusticia y la persona más injusta, para que, al poner atención en ellas (i.e. en esas personas), cómo se nos aparecerían no sólo respecto de la felicidad, sino también de su contrario, nos viéramos obligados incluso a reconocer respecto de nosotros mismos que quien fuera lo más semejante a ellas, tendrá el sino más semejante o parecido de aquélla (de la felicidad). Sin embargo, no era en vista de esto [que estábamos haciendo eso, a saber], para demostrar que estas cosas eran posibles.

Éste es un texto sorprendente y lleno de problemas (aunque, como en los casos anteriores, sólo me limitaré a comentar lo esencial y a omitir los problemas): lo justo en sí y el modelo de politeía (forma de organización política o régimen político) son irrealizables, seguramente porque son formas. Como algunos epistemólogos contemporáneos, Platón sostiene que si un modelo es realizable, deja de ser modelo y debe buscarse otro que oficie como tal. Pero la pregunta que uno debería hacerse es cuál es el valor y función de un modelo o paradigma que, además de ser perfecto como una forma, es irrealizable, especialmente en un contexto en el que lo que se quiere es encontrar la manera de organi-

${ }^{40}$ Según Natorp, la ley de lo lógico es anterior al ser concreto (un descubrimiento que atribuye explícitamente a Platón). Sin duda, la anterioridad en este caso no es temporal, sino lógico-ontológica. Éste es, en opinión de Natorp, el ABC del idealismo (cf. su 1903: 402). Por lo demás, la conexión que establece Natorp entre idea y ley tiene cierto apoyo textual en los diálogos: una idea o forma es para Platón algo que exhibe un cierto orden, de manera que no es raro que vincule las nociones de idea y forma a "orden" (táxis), "ley" (nómos) y "razón" (lógos; cf. República 587a y Filebo 26b; ambos pasajes son citados por Natorp, 1903: 211; 309). 
zar a los seres humanos del mejor modo posible. Lo que a mi juicio es claro en la tesis de Platón es que el mérito de un modelo no tiene nada que ver con la posibilidad de que sea realizado; no hay duda de que los modelos, entendidos como formas, tienen un enorme mérito (al menos en sede platónica), pues constituyen ítems explicativos (siendo esto así, la irrealizabilidad del modelo no tiene nada de peyorativo para Platón, como sí lo tiene para buena parte del sentido común y de los cientistas políticos contemporáneos). A pesar de lo que ya creía el materialismo antiguo y de lo que piensa el materialismo contemporáneo, las formas inmateriales son los factores que, en sentido estricto (como dice Platón en el Fedón) explican, causan, dan cuenta de una cosa o de un estado de cosas.

La tesis fuerte de Platón es que no es posible llevar a cabo algo tal y como se lo enuncia en el argumento (lógos), porque lo natural es que la acción (prâxis) se encuentre menos en contacto con la verdad que el discurso (léxis) ${ }^{41}$. Si esto se reconoce (y el personaje Glaucón en el diálogo, como tal vez algunos de nosotros, lo reconoce), no debe exigírsenos que los modelos o paradigmas se den en la práctica (érgon) absolutamente y tal como se los describía en el lógos. La condición de que sea posible llevar a la práctica el modelo es, una vez más, ser capaz de acercarse lo más posible al modelo, que formal y conceptualmente gobierna la construcción que queremos llevar a cabo en la "realidad" (dado que Platón está en las antípodas del pragmatismo, la palabra "realidad" debe ir entrecomillada: para Platón el dominio eidético es, como sabemos, más "real" que el de las ejemplificaciones senso-perceptibles de las formas). Lo sorprendente de este pasaje es, a mi juicio, la intuición filosófica de Platón que le permite advertir que un modelo, si efectivamente lo es, no puede realizarse en los mismos términos en que se lo enuncia. No deja de ser interesante observar que Platón es cuidadoso y matiza su afirmación con los giros "en caso de que existiera, y cómo sería si existiera" (se refiere a la persona completamente justa que sería una especie de ejemplificación sensible de la justicia en sí).

Siguiendo a Platón, uno podría pensar en un sentido "relativo" de realización del modelo: "acercarse lo más posible a él" (ésta es una expresión que, naturalmente, no está exenta de dificultades). Lo que cuenta dentro de la pólis platónica sana no es que uno sea completa o perfectamente justo, sino que lo sea lo más posible. Si uno llega a este estado,

\footnotetext{
${ }^{41}$ República 473a1-2.
} 
podrá decir que es justo, y si un número importante de personas reunidas por intereses comunes alcanzan ese estado o condición, se podría decir que el modelo de pólis sana se ha realizado. Si esto es así, el modelo platónico tiene, como las ideas kantianas, un valor regulativo: esto es, no es algo que pueda constituir nuestro mundo empírico (ya que es imposible ejemplificar el modelo en cualquier cosa dada de nuestra experiencia). Se trata más bien de que el modelo es imprescindible como una especie de desideratum que regula nuestras acciones en el sentido de una meta a la que hay que aspirar. En parte del discurso público actual este enfoque al menos se declama; claro que uno siempre esperaría que se cumpla, aunque más no sea "en la medida de lo posible".

\section{REFERENCIAS BIBLIOGRÁFICAS}

Boeri, M. D. "Mét' áneu sómatos eînai méte sôma ti he psyjé (Aristóteles, De Anima B 2. 414 a 19-20). A Propósito del Alcance de las Interpretaciones Funcionalistas de la Psicología Aristotélica y del Carácter Causal del Alma". Elenchos (Rivista di studi sul pensiero antico) XXX (2009) Fascicolo 1, 53-97.

"The Stoic Psychological Physicalism: An Ancient Version of the Causal Closure Thesis". The New Centennial Review X N ${ }^{\circ} 3$ (2010): 105-132.

Botter, B. La Necessità Naturale in Aristotele. Napoli: Loffredo Editori, 2009.

Charlton, W. "Aristotle's Definition of Soul". En T. Irwin (ed.), Aristotle. Metaphysics, Epistemology, Natural Philosophy. New York \& London: Garland Publishing, Inc., 1995, 244-260.

Cohen, S. M. "Hylemorphism and Functionalism". En M. C. Nussbaum y A. O. Rorty (eds.), Essays on Aristotle's 'De Anima'. Oxford: Oxford University Press, 1992, 57-73.

Gómez-Lobo, Alfonso. "Aristóteles y el Aristotelismo Antiguo". En J. Gracia (ed.), Concepciones de la Metafisica. Madrid: Ed. Trotta, 1998, 51-68.

Irwin, T. Aristotle's First Principles. Oxford: Clarendon Press, 1988.

Natorp, P. Platos Ideenlehre. Eine Einführung in den Idealismus. Leipzig: Verlag der Dürr'schen Buchhandlung, 1903.

Nussbaum, M. C. y H. Putnam. "Changing Aristotle's Mind". En M. C. Nussbaum y A. O. Rorty (eds.), Essay on Aristotle's De Anima. Oxford University Press, 1992.

Patzig, G. y M. Frede. Aristoteles. Metaphysic Z. Text, Übersetzung und Kommentar. München: C. H. Beck'sche Verlagsbuchhandlung, 1988 (2 vols.).

Putnam, H. "Philosophy and Our Mental Life". En H. Putnam, Mind, Language and Reality (Philosophical Papers, Volume 2). Cambridge: Cambridge University Press (reimpr. de la ed. de 1975), 1995, 291-303.

Whiting, J. "Living Bodies". En M. C. Nussbaum y A. O. Rorty (eds.), Essays on Aristotle's 'De Anima'. Oxford: Oxford University Press, 1992, 75-91. 